\title{
The Transformation Efficiency and Influencing Factors of High-Tech Enterprises' Technological Achievements
}

\author{
Jie Ling \\ Nanjing Normal University, Business School, Nanjing, China \\ Email: jieling.lynn@qq.com
}

How to cite this paper: Ling, J. (2020) The Transformation Efficiency and Influencing Factors of High-Tech Enterprises' Technological Achievements. Open Journal of Business and Management, 8, 696-712. https://doi.org/10.4236/ojbm.2020.82042

Received: February 13, 2020

Accepted: March 15, 2020

Published: March 18, 2020

Copyright ( $\odot 2020$ by author(s) and Scientific Research Publishing Inc. This work is licensed under the Creative Commons Attribution International License (CC BY 4.0).

http://creativecommons.org/licenses/by/4.0/

\section{(c) (i) Open Access}

\begin{abstract}
Considering the role of science and technology intermediary institutions in the transformation of technological achievements, this paper studies the transformation efficiency and influencing factors of high-tech enterprises' technological achievements in various provinces of China. Firstly, the DEA-BCC model is used to analyze the transformation efficiency of technological achievements of high-tech enterprises in 27 provinces of China. Then, the $\mathrm{T}$ test tests the significance of the factors affecting the efficiency of technological achievements. The study found that the transformation efficiency of high-tech industrial technology achievements in 5 provinces including Beijing at the frontier of efficiency; the main factors affecting the transformation efficiency of high-tech enterprises in different provinces are not the same, but the science and technology intermediary institution is the key factors affecting the efficiency. Comprehensively, the cost of technological transformation and the impact of new product development costs on the efficiency of technological achievements transformation are not significant.
\end{abstract}

\section{Keywords}

High-Tech Enterprises, Technology Transformation Efficiency, Science and Technology Intermediary Institutions, DEA, T-Test

\section{Introduction}

With innovation-driving national background, Chinese enterprises have shifted from extensive growth led by expansion to sustainable development led by quality and efficiency. The key to this change lies in the improvement of the company's inherent technological innovation capabilities. High-tech enterprises, tech- 
nology and knowledge intensive industries, are the main carriers and typical enterprises of technological innovation, and their development will become a strategic center in the next stage of practice [1]. According to data from the National Bureau Statistics, in 2016, the main business income of high-tech enterprises nationwide was 15.4 trillion $\mathrm{CNY}$, and the total profit reached 10.3 trillion CNY. At the same time, the state and enterprises have invested a lot of resources to promote the development of high-tech enterprises. In fact, if you increase the input and neglect the improvement of the innovation efficiency of the transformation of technological achievements, it will lead to enormous waste of scientific research results and the ineffectiveness of scientific research inputs into economic output [2]. Therefore, in the high-speed development stage of high-tech enterprises' technology research and development, the input-output efficiency of factors in the transformation of technological achievements and the optimization of resource allocation have also become important issues in the academic community.

The technological achievements are transformed into an important part of technological innovation. The research in China's academic area is mainly focused on the technological innovation process, and the research is mainly divided into three stages. In the first stage, scholars regarded the process of technological innovation as a "Technical Black Box", and directly evaluated the efficiency of technological innovation on the input and output of the "Black Box". Liu and Guan [3], Guo and Zhang [4] used DEA to evaluate the innovation performance of various regions in China. $\mathrm{Wu}$ [5] constructed a knowledge production function to study the impact of factors such as R \& D capital stock on the efficiency of knowledge production, and innovatively proposed the concept of $\mathrm{R}$ \& D capital stock. Based on the perspective of efficiency, Bai Junhong [6] used the stochastic frontier model to study the efficiency of government R \& D funding and other input factors, finding R \& D funding of government is remarkably positive to technical innovation efficiency. In the second stage, scholars further dug out the "Black Box" of technological innovation, and divided the process of technological innovation into two stages: technological research and development and technological transformation, and studied the performance of China's technological innovation by stages. Liu and Lee [7] used a three-stage DEA model to study the innovation efficiency of China's high-tech districts in 2012. Guan [8], Han [9], Yu [10], and Zheng [11] evaluated the innovation performance of China based on two-stage DEA. In the third stage, scholars used the stochastic frontier model and DEA to analyze the technological innovation efficiency of each subject in China, and at the same time analyzed the factors affecting efficiency from different angles [12] [13] [14] [15] [16]. However, the previous research mainly focused on the technology research and development stage, and lacked in-depth research on the technological achievement transformation stage.

Based on above, this study considers the role of technology intermediaries in the transformation of technological achievements, uses the DEA-BCC model to 
evaluate the efficiency of the technological transformation process of Chinese high-tech enterprises, and then combines T-test to analyze the factors that affect the transformation efficiency of technological achievements, providing a reference for enterprises to improve the efficiency of the transformation of technological achievements, and also providing a basis for the country to formulate policies for the development of technology markets and optimize resource allocation.

The paper is organized as follows. After the introduction, we introduce the methodology the paper use, which includes data envelopment analysis and T-test. Then describes the data collection method and explains the measurement we choose based on the previous research, show the summary statistics as well to verify validity of samples. Next we do data analysis to explore the efficient status of 27 provinces and select inefficient provinces to do T-test so that digs out the reason why these provinces are not efficient enough. Finally, the article concludes 4 main findings, corresponding practical implications and future research the word has opened up.

\section{Methodology}

\subsection{Research Framework}

The research in this paper is divided into two parts. The first part uses DEA to evaluate and analyze the technological transformation efficiency of 27 provinces in the country according to the input and output indicators. The second part uses the paired sample $\mathrm{T}$ test to extract the internal key indicators that affect the efficiency of technological achievement transformation, analyzes the influencing factors of technological achievement transformation efficiency of high-tech enterprises in different provinces, and proposes corresponding efficiency improvement paths.

\subsection{Research Method}

1) Data Envelopment Analysis

Data Envelopment Analysis (DEA) was proposed by A. Charnes and W.W. Cooper [17] [18] [19] [20], which is a non-parametric efficiency estimation method for "departments" or "units" (DMU) with multiple inputs, used as determine whether the DMU is located on the production frontier of the production possible set [21] [22] [23] [24] [25]. Commonly used DEA models are CCR and BCC models, which are used to deal with the efficiency evaluation problems under "constant returns to scale (CRS)" and "variable returns to scale (VRS)", respectively. Because the transformation of technological achievements has the characteristics of knowledge economy, it has caused the variability of scale returns of high-tech enterprises in different provinces, so this paper uses the BCC model. The model assumes that there are $n$ decision-making units, the decision-making units have input data $m$ and output data $s$, and the scale return of the first decision-making unit $k$ depends on the parameters $\mu_{0}$, the efficiency model is, 


$$
\begin{gathered}
\max W_{k p}=\left(\mu^{\mathrm{T}} Y_{k}-\mu_{0}\right) \\
\text { s.t. } \omega^{\mathrm{T}} X_{j}-\mu^{\mathrm{T}} Y_{j}+\mu_{0} \geq 0, j=1,2, \cdots, n, \\
\omega^{\mathrm{T}} X_{k}=1, \\
\omega \geq 0, \mu \geq 0, \mu_{0} \in E^{1}
\end{gathered}
$$

Modeling into dual form and adding slack variables $S^{-}, S^{+}$, then the dual model is:

$$
\begin{gathered}
\min \theta \\
\text { s.t. } \quad X \lambda+S^{-}=\theta X_{k} \\
Y \lambda-S^{+}=Y_{k} \\
\sum_{j=1}^{n} \lambda_{j}=1 \\
\lambda \geq 0, S^{-} \geq 0, S^{+} \geq 0
\end{gathered}
$$

thereinto, $X$ is the $m \times n$ matrix of input indicators, $X_{j}$ is the vector form of $j$ th input index, $x_{i j}$ is the $i$ th input indicator of $j$ th DMU, $x_{i j}>0$, $i=1,2, \cdots, m ; j=1,2, \cdots, n . V$ is the corresponding weight coefficient matrix of $X, \quad v_{i}$ is the weight coefficient of $i$ th input indicator, $i=1,2, \cdots, m$; $j=1,2, \cdots, n . Y$ is the $s \times n$ matrix of output indicators, $Y_{j}$ is the vector form of $j$ th output index, $y_{r j}$ is $r$ th output indicator of $j$ th DMU, $y_{r j}>0$, $r=1,2, \cdots, s ; j=1,2, \cdots, n . U$ is the corresponding weight coefficient matrix of $Y, u_{r}$ is the weight coefficient of $r$ th output indicator, $r=1,2, \cdots, s . \omega, \mu$ are Charnes-Cooper transformation, $t=\frac{1}{V^{\mathrm{T}} X_{k}} \quad, \quad \omega=t V=\left(\omega_{1}, \omega_{2}, \cdots, \omega_{m}\right)^{\mathrm{T}}$, $\mu=t U=\left(\mu_{1}, \mu_{2}, \cdots, \mu_{s}\right)^{\mathrm{T}}$.

According to the results of BCC model, the validity of DMU can be judged as rules following. If $W_{k P}=1$, then the DMU $k$ is weakly effective; if $W_{k P}=1$, $\omega>0, \mu>0$, the DMU is effective; if $W_{k P}=1$, the DMU is ineffective.

In addition, BCC model and CCR model together yield technical efficiency (TE), scale efficiency (SE), and pure technical efficiency (PTE) [26]. TE (comprehensive efficiency under the condition of constant returns to scale) represents the ability to achieve the maximum output under a given input or the minimum input under a given output. SE represents the extent to which economies of scale are exerted compared to scale effective units. PTE (Pure technical efficiency obtained with variable returns to scale) expresses the efficiency of eliminating scale factors. Relationship among them, TE $=\mathrm{SE} \times \mathrm{PTE}$. TRS is the indicator judged production scale returns, $T R S_{k}=1-\frac{\mu_{0}}{\sum_{r=1}^{s} u_{r} y_{r k}}$.

2) T-Test

T test is also called Student-T test, which suits for a normal distribution with a small sample size and an unknown overall standard deviation $\sigma$. In this paper, the paired sample $\mathrm{T}$ test is used to determine whether there is a significant dif- 
ference in the mean of the paired sample populations from which the paired samples come. Employing the notation $X_{0}, X_{1}$ are samples, $S$ is the standard deviation of $X_{0}-X_{1}$, then the statistic $t=\frac{\overline{\left(X_{0}-X_{1}\right)}}{S / \sqrt{n-1}}$.

Since the statistic $t$ follows a distribution with a degree of freedom of $n-1$, it can be judged according to the value of the $t$ statistic and the corresponding value $t_{0}$ in the $t$ statistical distribution table. If $t>t_{0}$, then reject the null hypothesis and consider that there is a significant difference between the two populations; if $t<t_{0}$ then accept the null hypothesis, consider that there is no significant difference between the two populations. In this paper, the conversion efficiency value of the technical results obtained by the model with the index removed is the control group $\left(X_{0}\right)$, and the efficiency value obtained by the model with the index removed is the experimental group $\left(X_{1}\right)$. The paper constructs $\mathrm{T}$ statistics and judge whether there is a significant difference in the pairing group. If there is no significant difference, the elimination index is not a key indicator that affects the conversion efficiency of technical results. If there is a significant difference, this index is a key indicator that affects the conversion efficiency of technical results.

\section{Data and Measurement}

\subsection{Data Collection}

The data in this article comes from the 2012-2016 Statistical Yearbook of China's High-Tech Industry and the National Technology Market Statistics Annual Report issued by the National Bureau of Statistics and the Torch High-Tech Industry Development Center of the Ministry of Science and Technology. Because the statistical data of the four provinces of Qinghai, Hainan, Inner Mongolia, and Tibet are missing in the data statistics, this article only selects 27 high-tech enterprises in the country.

\subsection{Measures}

Based on the references and the National Innovation Enterprise Report [27]-[32], combined with the characteristics of high-tech industries, the reliability, availability of data and the requirements of the DEA model comprehensively. The paper selects 6 input indicators and an output indicator from 4 aspects including technology, capital, labour and technology intermediary service agency, as shown in Table 1. The state of innovation investment, reflecting the orientation of corporate resource allocation, is an important indicator of corporate innovation awareness [33] [34]. The input indicators selected in this paper includes the number of domestic patent application grants, the number of valid invention patents, full-time equivalent of R \& D personnel by performance, new product development expense and technical transformation expense.

Since the time lag in the transformation of technical results is one year [13] [35] [36], the input indicators for this article start from 2012, and the output in- 
dicators start from 2013. In addition, the prerequisite for the use of DEA is that the number of DMUs should be at least two times the number of variables to ensure that the estimated efficiency value of the model is close to the true efficiency value [37]. The number of DMUs in this paper exceeds three times the number of variables. Therefore, the estimation result is reliable. The descriptive statistics of the original data in this paper are shown in Table 2.

\section{Data Analysis}

\subsection{Correlation Analysis}

First, the input-output index was analyzed by correlation coefficients, and the results are shown in Table 3. It can be seen from Table 3 that each index is significantly related and all passed the $1 \%$ significance level. Therefore, the index selected in this paper can be used for DEA in the stage of technical achievement transformation.

\subsection{DEA Efficiency Analysis of Technical Transformation}

The paper uses DEAP 2.1 to analyze the technological transformation efficiency of high-tech enterprises in 27 provinces from 2012 to 2015, the results are shown in Table 4.

Table 1. Indicators of technical transformation.

\begin{tabular}{lc}
\hline Input Indicator (Abbr./Unit) & $\begin{array}{c}\text { Output Indicator } \\
\text { (Abbr./Unit) }\end{array}$ \\
\hline The Number of Domestic Patent Application Grants (DPAG/pcs) & $x_{1}$ \\
The Number of Valid Invention Patents (VI/pcs) $x_{2}$ & Sales Revenue of \\
$\begin{array}{l}\text { Full-time Equivalent of R \& D Personnel by Performance } \\
\text { (RDP/person/year) } x_{3}\end{array}$ & $\begin{array}{c}\text { New Products(billion) y } \\
\text { The Number of National Technology Transfer Demonstration Agencies } \\
x_{4} \text { (NTTDA) }\end{array}$ \\
New Product Development Expense (NPDE/billion) $x_{5}$ & \\
Technical Transformation Expense (TTE/billion) $x_{6}$ & \\
\hline
\end{tabular}

Table 2. Summary statistics.

\begin{tabular}{cccccc}
\hline Variables & Obs & Mean & Std. Dev. & Min & Max \\
\hline$y$ & 108 & 1442.79 & 2631.05 & 1.89 & $15,542.82$ \\
$x_{1}$ & 108 & $47,200.52$ & $62,477.43$ & 844.00 & $269,944.00$ \\
$x_{2}$ & 108 & 6244.80 & $17,010.76$ & 12.00 & $125,471.00$ \\
$x_{3}$ & 108 & $25,117.02$ & $42,357.36$ & 66.00 & $224,334.00$ \\
$x_{4}$ & 108 & 14.10 & 11.91 & 1.00 & 58.00 \\
$x_{5}$ & 108 & 95.59 & 174.80 & 0.33 & 1070.73 \\
$x_{6}$ & 108 & 14.44 & 22.18 & 0.16 & 122.56 \\
\hline
\end{tabular}


Table 3. Correlation coefficient.

\begin{tabular}{cccccccc}
\hline Variables & $y$ & $x_{1}$ & $x_{2}$ & $x_{3}$ & $x_{4}$ & $x_{5}$ & $x_{6}$ \\
\hline$y$ & 1 & & & & & & \\
$x_{1}$ & $0.806^{* * *}$ & 1 & & & & & \\
$x_{2}$ & $0.904^{* * *}$ & $0.610^{* * *}$ & 1 & & & & \\
$x_{3}$ & $0.953^{* * *}$ & $0.797^{* * *}$ & $0.897^{* * *}$ & 1 & & & \\
$x_{4}$ & $0.524^{* * *}$ & $0.640^{* * *}$ & $0.432^{* * *}$ & $0.511^{* * *}$ & 1 & & \\
$x_{5}$ & $0.965^{* * *}$ & $0.781^{* * *}$ & $0.949^{* * *}$ & $0.966^{* * *}$ & $0.568^{* * *}$ & 1 & \\
$x_{6}$ & $0.658^{* * *}$ & $0.811^{* * *}$ & $0.376^{* * *}$ & $0.639^{* * *}$ & $0.464^{* * *}$ & $0.612^{* * *}$ & 1 \\
\hline
\end{tabular}

${ }^{* * *} p<0.01$ (2-tailed).

Table 4. 2012-2015 technical transformation efficiency.

\begin{tabular}{|c|c|c|c|c|c|c|c|c|c|c|c|c|c|}
\hline \multirow{2}{*}{ Prov. } & \multicolumn{3}{|c|}{2012} & \multicolumn{3}{|c|}{2013} & \multicolumn{3}{|c|}{2014} & \multicolumn{4}{|c|}{2015} \\
\hline & $\mathrm{TE}$ & PTE & SE & $\mathrm{TE}$ & PTE & SE & $\mathrm{TE}$ & PTE & SE & $\mathrm{TE}$ & PTE & SE & TRS \\
\hline Beijing & 0.70 & 0.71 & 0.98 & 1.00 & 1.00 & 1.00 & 1.00 & 1.00 & 1.00 & 0.97 & 0.97 & 1.00 & irs \\
\hline Tianjin & 1.00 & 1.00 & 1.00 & 1.00 & 1.00 & 1.00 & 0.95 & 1.00 & 0.95 & 1.00 & 1.00 & 1.00 & - \\
\hline Hebei & 0.17 & 0.23 & 0.71 & 0.20 & 0.33 & 0.62 & 0.20 & 0.32 & 0.61 & 0.22 & 0.35 & 0.63 & irs \\
\hline Shanxi & 0.09 & 0.71 & 0.13 & 0.14 & 0.71 & 0.19 & 0.16 & 0.56 & 0.29 & 0.16 & 0.81 & 0.20 & irs \\
\hline Liaoning & 0.22 & 0.25 & 0.90 & 0.25 & 0.28 & 0.90 & 0.22 & 0.26 & 0.84 & 0.31 & 0.34 & 0.92 & irs \\
\hline Jilin & 0.26 & 0.36 & 0.74 & 0.26 & 0.41 & 0.63 & 0.23 & 0.77 & 0.30 & 0.45 & 0.55 & 0.82 & irs \\
\hline Heilongjiang & 0.06 & 0.16 & 0.40 & 0.07 & 0.18 & 0.41 & 0.06 & 0.24 & 0.27 & 0.09 & 0.36 & 0.26 & irs \\
\hline Shanghai & 0.20 & 0.21 & 0.96 & 0.25 & 0.29 & 0.88 & 0.45 & 0.54 & 0.84 & 0.48 & 0.49 & 0.99 & irs \\
\hline Zhejiang & 0.27 & 0.27 & 0.97 & 0.25 & 0.25 & 1.00 & 0.27 & 0.27 & 1.00 & 0.33 & 0.36 & 0.91 & drs \\
\hline Anhui & 0.24 & 0.26 & 0.91 & 0.33 & 0.35 & 0.95 & 0.33 & 0.36 & 0.93 & 0.50 & 0.52 & 0.97 & irs \\
\hline Fujian & 0.50 & 0.51 & 0.99 & 0.39 & 0.41 & 0.97 & 0.38 & 0.39 & 0.97 & 0.43 & 0.43 & 0.99 & irs \\
\hline Jiangxi & 0.43 & 0.49 & 0.87 & 0.40 & 0.49 & 0.82 & 0.35 & 0.61 & 0.58 & 0.40 & 0.43 & 0.94 & irs \\
\hline Shandong & 0.33 & 0.33 & 0.99 & 0.31 & 0.32 & 0.99 & 0.43 & 0.43 & 1.00 & 0.50 & 0.50 & 1.00 & irs \\
\hline Henan & 1.00 & 1.00 & 1.00 & 1.00 & 1.00 & 1.00 & 1.00 & 1.00 & 1.00 & 1.00 & 1.00 & 1.00 & - \\
\hline Hubei & 0.27 & 0.28 & 0.94 & 0.29 & 0.32 & 0.91 & 0.33 & 0.36 & 0.94 & 0.35 & 0.37 & 0.96 & irs \\
\hline Hunan & 0.51 & 0.53 & 0.96 & 0.64 & 0.65 & 0.98 & 0.50 & 0.52 & 0.96 & 0.64 & 0.66 & 0.98 & irs \\
\hline Guangdong & 1.00 & 1.00 & 1.00 & 0.88 & 1.00 & 0.88 & 0.88 & 1.00 & 0.88 & 1.00 & 1.00 & 1.00 & - \\
\hline Sichuan & 0.30 & 0.32 & 0.95 & 0.34 & 0.35 & 0.98 & 0.30 & 0.31 & 0.97 & 0.41 & 0.41 & 0.99 & irs \\
\hline Guizhou & 0.21 & 1.00 & 0.21 & 0.23 & 1.00 & 0.23 & 0.12 & 0.56 & 0.22 & 0.17 & 0.58 & 0.29 & irs \\
\hline Yunnan & 0.19 & 1.00 & 0.19 & 0.20 & 0.51 & 0.39 & 0.12 & 0.68 & 0.18 & 0.16 & 0.36 & 0.44 & irs \\
\hline Shaanxi & 0.17 & 0.20 & 0.84 & 0.18 & 0.22 & 0.81 & 0.18 & 0.22 & 0.84 & 0.23 & 0.25 & 0.92 & irs \\
\hline Gansu & 0.16 & 1.00 & 0.16 & 0.44 & 1.00 & 0.44 & 0.19 & 0.59 & 0.33 & 0.65 & 1.00 & 0.65 & irs \\
\hline Ningxia & 0.42 & 1.00 & 0.42 & 0.26 & 1.00 & 0.26 & 0.42 & 1.00 & 0.42 & 0.58 & 1.00 & 0.58 & irs \\
\hline Xinjiang & 0.19 & 1.00 & 0.19 & 0.12 & 1.00 & 0.12 & 0.81 & 1.00 & 0.81 & 0.67 & 1.00 & 0.67 & irs \\
\hline
\end{tabular}

Because the scale returns from 2012 to 2014 are reflected in the data of the next year, the scale returns for these three years are not marked. 
According to Table 4, although the efficiency of the transformation of technological achievements in China has been steadily increasing from 2012 to 2015, the average efficiency still does not exceed 0.5 , and the transformation efficiency of technological achievements is low. The efficiency polarization of domestic high-tech enterprises' technological transformation is severe. The efficiency value of high-efficiency enterprises is always above 0.9 , but the efficiency of technological achievement transformation in most provinces is between $0.1-0.4$, especially for Heilongjiang high-tech enterprises. The average result of transformation efficiency is only 0.073 , which are all non-DEA valid.

From 2012 to 2015, the provinces where high-tech enterprise DEA is effective are Beijing, Tianjin, Henan, Guangdong, and Chongqing. Among them, the technological transformation efficiency of Henan has always been at the frontier of efficiency, and the transformation efficiency of technological achievements into economic output is relatively high. Investigating the reasons, on the one hand, the sales revenue of new products, the number of domestic patent applications authorized, the number of valid invention patents, the cost of technological transformation, the full-time equivalent of R \& D agency personnel, and the number of national technology transfer demonstration organizations have all shown a steady increase matching with each other. On the other hand, effective technology service organizations in the technology market keep technology intermediaries in a more active state. Beijing, Tianjin, and Guangdong, as provinces with concentrated national technological resources, are still at a stage of high technological achievement transformation efficiency, although the efficiency of technological achievement transformation has shown slight fluctuations. Besides, the transformation efficiency of Chongqing's technological achievements is in a state of rapid growth.

\subsection{T-test of Key Influence Factors to Technical Transformation}

Based on the analysis of the technological achievement transformation efficiency of high-tech enterprises in 27 provinces last chapter, this paper further conducts a T-test to remove the indicators in sequence to analyze the factors affecting the technological achievement transformation efficiency of high-tech enterprises in different provinces. First, this article removes input indicators in order: domestic patent application authorizations, effective invention patents, R \& D agency staff full-time equivalents, national technology transfer demonstration institutions, new product development costs, and technological transformation costs. Then use the same input-type BCC model was used to analyze the technical efficiency conversion efficiency of each DMU from 2012 to 2015. In order to reduce the non-systematic error of the transformation efficiency, the paper averages transformation efficiency of the four-year technical results corresponding to each DMUs to obtain TE1 and TE2, respectively, TE3, TE4, TE5, TE6. The results are shown in Table 5.

The 6 models are further paired with TE0 in order to perform a sample T test. 
If the model corresponding to an indicator is excluded and the test result is significant, the indicator is a key indicator that affects the efficiency of technical achievement conversion. Otherwise, it is a non-key indicator. As shown in Table 6.

In the 6 pairs of samples $T$ test, pair $1(p=0.005)$, pair $3(p=0.001)$ were significant at the $1 \%$ significance level, and group $2(p=0.050)$ was at the $5 \%$ level. Group $4(\mathrm{p}=0.077)$ is significant at a significance level of $10 \%$, but not significant for Group 5 and Group 6, namely new product sales revenue, domestic patent application authorizations, number of valid invention patents, R \& D institutions the full-time equivalent of personnel and the number of national technology

Table 5. TE of control and experimental groups.

\begin{tabular}{|c|c|c|c|c|c|c|c|}
\hline Prov. & TE0 & TE1 & TE2 & TE3 & TE4 & TE5 & TE6 \\
\hline Beijing & 0.92 & 0.92 & 0.92 & 0.83 & 0.92 & 0.92 & 0.47 \\
\hline Tianjin & 0.99 & 0.98 & 0.99 & 0.99 & 0.99 & 0.99 & 0.86 \\
\hline Hebei & 0.20 & 0.19 & 0.20 & 0.19 & 0.20 & 0.20 & 0.20 \\
\hline Shanxi & 0.14 & 0.14 & 0.14 & 0.12 & 0.14 & 0.13 & 0.14 \\
\hline Liaoning & 0.25 & 0.23 & 0.25 & 0.23 & 0.25 & 0.25 & 0.25 \\
\hline Jilin & 0.30 & 0.27 & 0.30 & 0.28 & 0.30 & 0.30 & 0.30 \\
\hline Heilongjiang & 0.07 & 0.07 & 0.07 & 0.06 & 0.07 & 0.07 & 0.07 \\
\hline Shanghai & 0.35 & 0.34 & 0.35 & 0.32 & 0.34 & 0.35 & 0.25 \\
\hline Jiangsu & 0.56 & 0.56 & 0.56 & 0.56 & 0.48 & 0.56 & 0.56 \\
\hline Zhejiang & 0.28 & 0.28 & 0.28 & 0.25 & 0.25 & 0.28 & 0.28 \\
\hline Anhui & 0.35 & 0.35 & 0.35 & 0.22 & 0.35 & 0.35 & 0.35 \\
\hline Fujian & 0.43 & 0.34 & 0.42 & 0.43 & 0.43 & 0.43 & 0.43 \\
\hline Jiangxi & 0.40 & 0.28 & 0.39 & 0.39 & 0.40 & 0.40 & 0.40 \\
\hline Shandong & 0.39 & 0.33 & 0.39 & 0.39 & 0.39 & 0.39 & 0.39 \\
\hline Henan & 1.00 & 1.00 & 1.00 & 1.00 & 1.00 & 1.00 & 1.00 \\
\hline Hubei & 0.31 & 0.19 & 0.30 & 0.31 & 0.31 & 0.31 & 0.31 \\
\hline Hunan & 0.57 & 0.51 & 0.57 & 0.50 & 0.57 & 0.57 & 0.57 \\
\hline Guangdong & 0.94 & 0.94 & 0.94 & 0.94 & 0.82 & 0.94 & 0.94 \\
\hline Guangxi & 0.25 & 0.25 & 0.25 & 0.18 & 0.25 & 0.25 & 0.25 \\
\hline Chongqing & 0.64 & 0.64 & 0.64 & 0.41 & 0.64 & 0.64 & 0.64 \\
\hline Sichuan & 0.34 & 0.33 & 0.34 & 0.25 & 0.34 & 0.34 & 0.34 \\
\hline Guizhou & 0.18 & 0.18 & 0.18 & 0.18 & 0.15 & 0.18 & 0.18 \\
\hline Yunnan & 0.17 & 0.17 & 0.17 & 0.12 & 0.17 & 0.17 & 0.15 \\
\hline Shaanxi & 0.19 & 0.11 & 0.19 & 0.19 & 0.19 & 0.19 & 0.19 \\
\hline Gansu & 0.36 & 0.36 & 0.32 & 0.31 & 0.36 & 0.36 & 0.26 \\
\hline Ningxia & 0.42 & 0.42 & 0.37 & 0.39 & 0.42 & 0.42 & 0.42 \\
\hline Xinjiang & 0.45 & 0.45 & 0.45 & 0.25 & 0.45 & 0.45 & 0.45 \\
\hline
\end{tabular}

TE0 is the mean of efficiency under original input and output. 
Table 6. Paired-samples T-tests.

\begin{tabular}{|c|c|c|c|c|c|c|c|c|c|}
\hline \multirow{3}{*}{\multicolumn{2}{|c|}{$\begin{array}{l}\text { Control } \\
\text { Group-Experimental } \\
\text { Group }\end{array}$}} & \multicolumn{5}{|c|}{ Variance } & \multirow{3}{*}{$\mathrm{T}$} & \multirow{3}{*}{ df } & \multirow{3}{*}{$\begin{array}{c}\text { Sig. } \\
\text { (two-tail }\end{array}$} \\
\hline & & \multirow{2}{*}{ Mean } & \multirow{2}{*}{ Std. } & \multirow{2}{*}{ SEM } & \multicolumn{2}{|c|}{ 95\% C.I. } & & & \\
\hline & & & & & Upper & Lower & & & \\
\hline No.1 & TE0-TE1 & 0.02 & 0.04 & 0.01 & 0.01 & 0.04 & 3.10 & 26 & 0.005 \\
\hline No. 2 & TE0-TE2 & 0.01 & 0.01 & 0.00 & 0.00 & 0.01 & 2.06 & 26 & 0.050 \\
\hline No.3 & TE0-TE3 & 0.04 & 0.06 & 0.01 & 0.02 & 0.07 & 3.69 & 26 & 0.001 \\
\hline No. 4 & TE0-TE4 & 0.01 & 0.03 & 0.01 & 0.00 & 0.02 & 1.85 & 26 & 0.077 \\
\hline No. 5 & TE0-TE5 & 0.00 & 0.00 & 0.00 & 0.00 & 0.00 & 1.05 & 26 & 0.304 \\
\hline No.6 & TE0-TE6 & 0.03 & 0.09 & 0.02 & -0.01 & 0.07 & 1.69 & 26 & 0.104 \\
\hline
\end{tabular}

transfer demonstration organizations are key indicators that affect the efficiency of the transformation of technological achievements, while new product development expense and technological transformation expense are non-key indicators.

The changes in the transformation efficiency of technical achievements from 2012 to 2014 are reflected in the results of the following year. Therefore, this article selects the results of the 2015 DEA analysis to analyze the problems and suggestions in the technological achievements transformation stage of each province. Based on Table 6 and Table 7, the paper will analyze the reasons for the low efficiency in the transformation of technological achievements at the current stage except 3 provinces that are effective next.

According to Table 7, the reasons for the low efficiency of the technological achievements of China's high-tech enterprises can be divided into four categories,

First of all, the mode of technological patent achievements is redundant, and the mode of high technological research and development efficiency but low technological transformation efficiency results in patent hoarding. The redundancy of technological patent achievements is the main reason for the low efficiency of technological achievements in national high-tech enterprises. Among 24 provinces in which the technological efficiency of technological achievements is inefficient, the main reason for the inefficiency of 13 provinces is technological redundancy, accounting for $54.10 \%$. Thereof the main reason for the inefficiency of high-tech enterprises in Beijing, Shanxi, Zhejiang, Guangxi, and Guizhou is the redundancy of domestic patent application authorizations. Due to the gap in the level of technological research and development and technological achievement transformation, there is a high level of technological research and development efficiency, strong motivation, while technological achievement transformation is low-efficiency and weak-powered. During the one-year lag period studied in this paper, newly-approved patents could not be fully developed into new products and became redundant variables on the fault of technological research and development. Beijing, Shanxi, Liaoning, Shanghai, Anhui, Fujian In Jiangxi, Chongqing, Sichuan, Yunnan, there is a widespread phenomenon of 
Table 7. Slack variable of input indicator.

\begin{tabular}{|c|c|c|c|c|}
\hline Province & DPAG & VI & RDP & NTTDA \\
\hline Beijing & $57.30 \%^{*}$ & $67.63 \%^{*}$ & $0.00 \%$ & $79.90 \% *$ \\
\hline Hebei & $3.89 \%$ & $0.00 \%$ & $5.52 \%^{*}$ & $0.00 \%$ \\
\hline Shanxi & $37.84 \%^{*}$ & $35.34 \%^{*}$ & $37.92 \%^{*}$ & $0.00 \%$ \\
\hline Liaoning & $0.00 \%$ & $22.30 \%^{*}$ & $0.00 \%$ & $19.53 \%$ \\
\hline Jilin & $0.00 \%$ & $26.25 \%$ & $0.00 \%$ & $30.60 \%$ * \\
\hline Heilongjiang & $13.08 \%$ & $0.00 \%$ & $17.25 \%^{*}$ & $0.00 \%$ \\
\hline Shanghai & $6.28 \%$ & $27.65 \%^{*}$ & $0.00 \%$ & $12.65 \%$ \\
\hline Jiangsu & $0.00 \%$ & $0.00 \%$ & $0.00 \%$ & $0.00 \%$ \\
\hline Zhejiang & $11.54 \%^{*}$ & $7.72 \%$ & $0.00 \%$ & $3.15 \%$ \\
\hline Anhui & $15.04 \%$ & $35.73 \% *$ & $0.00 \%$ & $0.00 \%$ \\
\hline Fujian & $0.00 \%$ & $21.11 \%^{*}$ & $0.00 \%$ & $4.55 \%$ \\
\hline Jiangxi & $0.95 \%$ & $16.50 \%^{*}$ & $0.00 \%$ & $0.00 \%$ \\
\hline Shandong & $0.00 \%$ & $0.00 \%$ & $3.34 \%$ & $27.38 \%$ * \\
\hline Hubei & $0.00 \%$ & $0.00 \%$ & $4.98 \%$ & $23.45 \%^{*}$ \\
\hline Hunan & $0.00 \%$ & $0.00 \%$ & $18.62 \%$ & $24.67 \%^{*}$ \\
\hline Guangxi & $35.13 \%^{*}$ & $0.00 \%$ & $7.36 \%$ & $0.00 \%$ \\
\hline Chongqing & $27.30 \%$ & $29.00 \% *$ & $0.00 \%$ & $0.00 \%$ \\
\hline Sichuan & $5.81 \%$ & $31.48 \%^{*}$ & $0.00 \%$ & $0.64 \%$ \\
\hline Guizhou & $36.57 \%^{*}$ & $12.57 \%$ & $30.21 \%$ & $0.00 \%$ \\
\hline Yunnan & $7.25 \%$ & $16.84 \%^{*}$ & $0.00 \%$ & $0.00 \%$ \\
\hline Shaanxi & $0.00 \%$ & $0.00 \%$ & $5.81 \%$ & $16.52 \%^{*}$ \\
\hline Gansu & $0.00 \%$ & $0.00 \%$ & $0.00 \%$ & $0.00 \%$ \\
\hline Ningxia & $0.00 \%$ & $0.00 \%$ & $0.00 \%$ & $0.00 \%$ \\
\hline Xinjiang & $0.00 \%$ & $0.00 \%$ & $0.00 \%$ & $0.00 \%$ \\
\hline
\end{tabular}

${ }^{*}$ The main indicators that affect the efficiency of high-tech enterprises's technological achievements.

inefficient invention patent technology redundancy that leads to inefficient transformation of technological achievements. This is due to the emphasis on the input-output performance of the technology research and development stage in technology innovation, and the technology is ignored after the technology patent is authorized, resulting in the accumulation of effective invention patents, but cannot be applied to new products.

Second, the role of R \& D personnel has not been brought into full play. For Hebei, Shanxi, Heilongjiang, one of the main reason for the low technical efficiency of high-tech enterprises is that the size of R \& D personnel is too large. The rate of underutilization of R \& D personnel in Shanxi is as high as $37.92 \%$. The main reason may be that the definition of $\mathrm{R} \& \mathrm{D}$ personnel is ambiguous, including scientific researchers and technical achievement transformation per- 
sonnel, which work together in the entire process of technological innovation, rather than precise in the process of technological achievement transformation. Besides, there is a large demand for talents who are familiar with the high-end of technological transformation in high-tech enterprises, but the imbalance between the supply and demand of such talents in the market causes the supply of talents in the market to be unable to meet the needs, leading to mismatches in academic qualifications, talent structure, technical capabilities, and positions [38] [39]. Finally, insufficient incentive mechanism for technical talents and their insufficient incentives also lead to low motivation.

Third, the effective activity of technology intermediary service agencies is relatively low. The key reason for the low technical efficiency of high-tech enterprises in the 7 provinces of Beijing, Jilin, Shandong, Hubei, Hunan, and Shaanxi is the low activated level of activity of technology transfer demonstration institutions. The main reason is that China's technological achievement transformation market has a late start and low maturity. The demand for technological achievement transformation of high-tech enterprises and the supply of technological intermediaries cannot fully match, and the technological intermediary service agencies have not fully played a role in the technological achievement transformation market.

Fourth, the scale of the construction of the technological achievement transformation market does not match the development level of the technological market. The slack variables in Jiangsu, Gansu, Ningxia, and Xinjiang are all 0. Because the PTE of these 4 provinces has reached 1, that is, without considering scale returns, their management and technology factors have fully played their role. But their scale efficiency is less than 1 , and there are different levels of problem that technology market scale is mismatching with the degree of technology development. Jiangsu's scale returns are diminishing, and the technology market scale is far ahead of the current technology market maturity. There is a phenomenon of over-construction of technological achievements to transform the market in Jiangsu. If the scale of the market continues to increase, the marginal economic benefits will decline. To maximize the effectiveness, technically active technology intermediary service agencies should be established, technical cooperation with surrounding areas should be formed, and advanced patented technologies should be introduced to develop technology to achieve a win-win situation. While the other three provinces are increasing in scale returns, so the expansion will bring about an increase in marginal economic benefits and an increase in market utility.

In addition, Beijing and Shanxi have inefficient multi-factor technological results. The reasons for the efficiency of Beijing's technological achievements transformation include the existence of an efficiency fault between technological research and development and the transformation of technological achievements, that is, patent output is strongly motivated but technological transformation efficiency is not efficient enough, and low effective third-party technology 
service intermediary markets. The reasons for the low efficiency of the transformation of technological achievements in Shanxi are in addition to the unilateral emphasis on the improvement of the efficiency of scientific research output and the neglect of the construction of the technological achievements transformation market, as well as the inadequate development and utilization of R \& D personnel. High-tech enterprises in both provinces should balance the development of various investment indicators and improve the efficiency of technological transformation in an all-round and multi-angle way. The reasons for the low efficiency of technological transformation in the other provinces are all single factors. Adjusting the configuration of this element accordingly can increase the efficiency of technological transformation precisely.

\section{Discussion and Implication}

\subsection{Main Findings}

Based on the DEA and paired sample T test, this paper evaluates the technological transformation efficiency of 27 provinces in China, analyzes the factors that affect the efficiency, and draws the following conclusions:

First of all, although China has made some improvements in the efficiency of technology research and development in recent years, the research and development achievements have been remarkable, but the efficiency of technology achievement transformation in our country is still relatively low. The efficiency of technology achievement transformation in 27 provinces across the country is only Beijing, Tianjin, Henan, and Guangdong. In Chongqing, it can be seen that the level of technological achievement transformation is still at a lower level of development, and the technological achievements have not been effectively transformed into economic benefits.

Secondly, the main reasons for the low efficiency of high-tech enterprises' transformation of technological achievements in different regions are different, but the increase in new product development costs and technological transformation expenses cannot cause a significant increase in the transformation efficiency of technological achievements. This is due to the late start of China's technological achievements transformation market and the lower marginal utility of funds.

Finally, due to the low efficiency of the transformation of technological achievements and the high efficiency of the technological research and development stage, there is a redundant phenomenon of technological achievements in most provinces across the country. Specifically, the phenomenon of low technological transformation efficiency in 27 provinces in China can be divided into four categories: First, in Beijing, Shanxi, Zhejiang, Guangxi, Guizhou, Liaoning, Shanghai, Anhui, Fujian, Jiangxi, Chongqing, Sichuan, and Yunnan, 13 high-tech companies in each province have redundant technical results due to the unbalanced development of the two stages of technological innovation. They overemphasize technological research and development and ignore the process 
of converting technological achievements into new products. Second, the high-tech enterprises in the three provinces of Hebei, Shanxi, and Heilongjiang have not made full use of the role of R \& D personnel, resulting in low efficiency in the transformation of technological results. Third, Beijing, Jilin, Shandong, Hubei, Hunan, and Shaanxi have a low level of effective activity in the market for third-party technology intermediary service agencies, which has led to asymmetric and incomplete information in the technical results trading market. Fourth, the high-tech enterprises in the four provinces of Jiangsu, Gansu, Ningxia, and Xinjiang have not fully developed the technological achievement transformation market due to the mismatch in the scale of technological achievement transformation market construction and technological market development.

\subsection{Implication}

Based on the above conclusions, this article makes the following suggestions.

First, balance the two stages of technological innovation. The technological research and development stage and technological achievement transformation stage of technological innovation are mutually coupled. One-sided emphasis on technological research and development will lead to a large accumulation of patents and the investment in research and development cannot be effectively converted into economic returns.

Second, give full play to the role of relevant talents. Enterprises should examine whether there is a phenomenon of talent abuse and mismatch of personnel themselves in advanced. Then ban virtual posts, recruit talents according to job needs, formulate a comprehensive talent management and development system, and clarify talent incentive policies, give full play to the role of on-the-job talents, promote the development of the market for the transformation of technological achievements, and improve the quality and professional level of talents.

Third, give full play to the role of science and technology intermediaries. When the government guides the development of the technology intermediary structure, it should avoid the impact of vicious competition events and arbitrage on the market. In addition, the training of science and technology intermediary talents should be strengthened.

Fourth, coordinate the size of the technology market and the maturity of the market for the transformation of technological achievements, so as to adapt the two. The eastern region chooses the size of the technology market according to the development level of the technology achievement transformation market. At the stage of decreasing technological transformation returns, it is necessary to support the development of new product development expenses, technical talents, technology intermediary service institutions in the technology market, to join the active markets of neighboring cities and fully absorbing both parties in the technology market and technology patents to match existing technology achievements scale. The western region should absorb technical talents, introduce advanced technologies, and increase the scale of technological transforma- 
tion continuously, tap the market potential, and fully transform technology patents to obtain the internal driving force of economic development.

\subsection{Limitation and Future Research}

The study has certain limitations below. 1) Indicators of intermediary are not comprehensive enough. Because intermediary is a new indicator of State Statistics Bureau since 2016, and the institution constantly improves accuracy of the indicators so the measurement of the intermediary is under further exploration. 2) Based on the results of DEA, the article did a t-test to decide key factors of technological transformation efficiency, while T-teat can only research whether an indicator is a key factor and the degree of the indicator influencing the efficiency, which is not deep enough. 3) The article studies the efficiency of the Chinese technological achievement transformation and finds there is a huge gap between the development of technological innovation and transformation, which improve the need to do further and systematic research of the market.

According to the limitation and the results of the article, we shall also continue to do a systematic and further research, which combines the two stages of technological innovation, and accurate improving path on the basis of different innovative status.

\section{Conflicts of Interest}

The author declares no conflicts of interest regarding the publication of this paper.

\section{References}

[1] Lee, W.M. and Zhang, Y. (2016) Evaluation and Countermeasures of Technological Innovation Competitiveness in Northeast China. Journal of Liaoning University (Philosophy and Social Science Edition), 44, 90-97.

[2] Qian, L., Xiao, R.Q. and Chen, Z.W. (2015) Research on Innovation Efficiency and Regional Differences of Green Technology in China's Industrial Enterprises-Based on Common Frontier Theory and DEA Model. Economic Theory and Economic Management, 35, 26-43.

[3] Liu, S.Z. and Guan, J.C. (2002) Evaluation of Innovation Performance of Regional Innovation System. China Management Science, 10, 75-78.

[4] Guo, S.F. and Zhang, J. (2018) Comparison of Technology Innovation Efficiency and Input Redundancy in 31 Provinces and Cities in China. Scientific Research Management, 39, 55-63.

[5] Wu, Y.B. (2006) R \& D Stock, Knowledge Function and Production Efficiency. Economics (Quarterly), 5, 1129-1156.

[6] Bai, J.H. and Li, J. (2011) Empirical Analysis of Government R \& D Funding and Enterprise Technology Innovation Based on Efficiency Perspective. Financial Research, 6, 181-193.

[7] Liu, M.F. and Li, S.H. (2016) Research on the Innovation Efficiency of China's High-Tech Development Zones Based on the Three-Stage DEA Model. Management Review, 28, 142-155. 
[8] Guan, J.C. and He, Y. (2005) Evaluation of Regional Innovation System Based on DEA Method. Studies in Science of Science, 23, 265-272.

[9] Han, B. and Su, Y. (2018) Research on Technology Innovation Performance of High-Tech Enterprises Based on Two-Stage DEA. Scientific Research Management, 39, 11-19.

[10] Yu, Y.C., Gu, X. and Chen, Y.J. (2017) "Black Box" Deconstruction and Efficiency Evaluation of Industry-University-Research Technology Transfer. Scientific Research Management, 38, 28-37.

[11] Zheng, J. and Ding, Y.L. (2008) Analysis of the Marginal Revenue Characteristics and Efficiency of Technological Innovation in High-Tech Industry. Studies in Science of Science, 26, 1090-1097.

[12] Yu, W.J. (2015) Research on the Innovation Efficiency and Influencing Factors of Regional High-Tech Industries Based on Two-Stage Serial DEA. Research and Development Management, 27, 137-145.

[13] Li, H.X. and Chi, G.T. (2016) Evaluation of the Efficiency of Technological Innovation Based on Enterprises Based on DEA-T Test. China Management Science, 24, 109-119.

[14] Yu, Y.B. and Liu, L.Y. (2016) Analysis of China's Urban Environmental Performance and Its Influencing Factors. Management World, 11, 176-177.

[15] Jiang, R.A., Gao, C.L. and Feng, G.F. (2013) Research on the Evaluation of Technology Resource Utilization Efficiency of Chinese Research Institutions. Statistical Research, 30, 19-29.

[16] Shen, N. and Zhou, J.J. (2018) Research on the Efficiency and Key Factors of Green Innovation in China from the Perspective of Technology Heterogeneity: Based on Hybrid DEA and Structured Equation Model. Journal of Management Engineering, 4, 46-53.

[17] He, D.F. (2011) Discrimination and Reflection on Some Basic Concepts of Scientific and Technological Achievements and Their Transformation. China Soft Science, 11, 1-7.

[18] Charnes, A. and Cooper, W.W. (1978) Rhodes E. Measuring the Efficiency of Decision Making Units. European Journal of Operational Research, 2, 429-444. https://doi.org/10.1016/0377-2217(78)90138-8

[19] Banker, R.D., Charnes, A. and Cooper, W.W. (1984) Some Models for Estimating Technical and Scale Inefficiencies in Data Envelopment Analysis. Management Science, 30, 1078-1092. https://doi.org/10.1287/mnsc.30.9.1078

[20] Charnes, A., Cooper, W.W., Golany, B. and Seiford, L. (1985) Foundation of Data Envelopment Analysis for Pareto-Koopmans Efficient Empirical Production Functions. Journal of Econometrics, 30, 91-107. https://doi.org/10.1016/0304-4076(85)90133-2

[21] Kou, M., Chen, K., Wang, W. and Shao, Y. (2016) Measuring Efficiencies of Multi-Period and Multi-Division Systems Associated with DEA: An Application to OECD Countries' National Innovation Systems. Expert Systems with Applications, 46, 494-510. https://doi.org/10.1016/j.eswa.2015.10.032

[22] Lu, W.M. and Qian, L.K. (2014) Intellectual Capital and National Innovation Systems Performance. Knowledge-Based Systems, 71, 201-210. https://doi.org/10.1016/j.knosys.2014.08.001

[23] Sueyoshi, T. and Goto, M. (2014) Environmental Assessment for Corporate Sustainability by Resource Utilization and Technology Innovation: DEA Radial Mea- 
surement on Japanese Industrial Sectors. Energy Economic, 46, 295-307. https://doi.org/10.1016/j.eneco.2014.09.021

[24] Goto, M., Otsuka, A. and Sueyoshi, T. (2014) DEA Assessment of Operational and Environmental Efficiencies on Japanese Regional Industries. Energy, 66, 535-549. https://doi.org/10.1016/j.energy.2013.12.020

[25] Shen, N. and Wang, Q.W. (2013) Spatial Model of China's Energy Efficiency and Differentiated Energy Saving Paths-Analysis Based on DEA Three Stage Model. System Science and Mathematics, 33, 457-467.

[26] Wei, Q.L. (2004) Data Envelope Analysis. Science Press, Beijing.

[27] Liu, X.Z., Huang, J. and Wang, Y. (2017) Analysis of Energy Efficiency in Iron and Steel Industry Based on DEA Cross Efficiency Model. World of Management, 10, 182-183.

[28] Wang, F. and Li, H. (2013) Evaluation of Regional Technology Transfer Efficiency in China Based on DEA. Science Research Management, 1, 153-160.

[29] Zheng, Z., Yang, R.Y. and Ji, Q.Q. (2017) Fifteen-Year Review and Prospect of Domestic and Foreign Research Literature on Enterprise Innovation Performance. China Technology Forum, 3, 73-80.

[30] Zhang, J.X. (2010) Measurement of the Development Degree of China's Technology Market. Scientific Research Management, 31, 79-89.

[31] Bai, J.H., Jiang, K.S. and Li, J. (2009) Analysis of the Environmental Impact Factors of Regional Innovation Efficiency-An Empirical Test Based on the Two-Step Method of DEA-Tobit. Research and Development Management, 21, 96-101.

[32] Editorial Board of China Innovative Enterprise Development Report (2015) 2013-2014 China Innovative Enterprise Development Report. Economic Management Press, Beijing.

[33] Zhang, X.M., Wang, Y.M. and Shi, H.L. (2018) Research on Optimal Allocation of Key Resources of Innovative Enterprises from the Perspective of Efficiency. Science Research Management, 5, 103-111.

[34] Chai, W., Shen, W. and Mao, Y.L. (2015) Research on Performance Evaluation of Technology Innovation of Resource-Based Enterprises in China Based on DEA. Science Research Management, 36, 28-34.

[35] Li, M.N. (2017) Research on the Evaluation Model of Innovation Efficiency Based on the Decoupling Perspective of "R \& D-Transformation". Science of Science and Technology Management, 38, 50-67.

[36] Fan, H. and Zhou, D.Q. (2012) Research on the Evolution of Technological Innovation Efficiency and Its Influencing Factors in China. Science Research Management, 33, 10-18.

[37] Golany, B. and Roll, Y. (1989) An Application Procedure for DEA. Omega, 17, 237-250. https://doi.org/10.1016/0305-0483(89)90029-7

[38] Xie, Z.Y. (2011) Research on the Influencing Factors of National High-Tech Innovation Efficiency. Science Research Management, 32, 52-58.

[39] Gong, F. (2008) Assessment of the Efficiency of Local Public Safety Service Supply-An Empirical Study of the Bootstrapped DEA Based on Four-Stage DEA. Management World, 4, 80-90. 